\title{
O programa de alimentação escolar no estado de Mato Grosso: da centralização à descentralização (1979 - 1995)
}

\author{
The school meal program in the state of Mato Grosso from \\ centralization to decentralization (1979 - 1995)
}

Maria Angélica dos Santos SPINELLI ${ }^{1}$

Ana Maria CANESQUI²

RE S U M O

Este artigo analisa a constituição, organização institucional e desempenho do programa de alimentação escolar no Estado de Mato Grosso no período de 1979 a 1995. São enfatizados os seguintes aspectos: o período de transição do modelo de gestão centralizada à descentralizada; as influências das agências federais nas intervenções estaduais; as prioridades e ações das gestões dos governos mato-grossenses. Este estudo reconstitui e analisa o desempenho de uma política assistencial, valendo-se da coleta e análise de dados secundários e primários (20 entrevistas com agentes institucionais). Os resultados mostram a estreita dependência das intervenções estaduais das federais e o deslocamento do modelo centralizado para o descentralizado. A dinâmica, intensidade e ritmo desta mudança foram influenciados, de um lado, pelas estratégias federais e, de outro, pelas prioridades, graus de anuência e capacidades institucionais dos governos estaduais, desempenhando-se heterogeneamente o programa quanto ao número de municípios, dias letivos cobertos, clientela atendida, gastos e alimentos consumidos per capita/ano e modalidades de descentralização.

Termos de indexação: alimentação escolar, programas e políticas de nutrição e alimentação, centralização, descentralização.

A B S T R A C T

This article analyzes the establishment, the institutional organization and the performance of the school meal program in the state of Mato Grosso from 1979 to 1995. The following aspects are emphasized: the transition period from a centralized management model to a decentralized one; the influence of the federal agencies on

1 Pós-Graduação Saúde e Ambiente, Instituto de Saúde Coletiva, Universidade Federal de Mato Grosso. Av. Fernando Correia, s/n, 78060-900, Cuiabá, MT, Brasil. Correspondência para/Correspondence to: M.A.S.SPINELLI.

2 Departamento de Medicina Preventiva e Social, Faculdade de Ciências Médicas, Universidade Estadual de Campinas; Programa de Pós-Graduação em Saúde e Ambiente, Instituto de Saúde Coletiva, Universidade Federal de Mato Grosso. 
106 | M.A.S. SPINELLI \& A.M. CANESQUI

the state interventions; the priorities and the actions of the government's of Mato Grosso. This study reconstructs and analyzes the performance of a welfare policy, using the collection and analysis of secondary and primary data (20 interviews with institutional agents). The results show a close dependence of the state interventions on the federal ones and a change from a centralized model to a decentralized one. The dynamics, the intensity and the rhythm of this modification were influenced by both the federal strategies and the priorities, degrees of acquiescence and institutional capacities of the state governments. The program was developed heterogeneously concerning the number of towns involved, the school days covered, the pupils attended, the cots and the consumed foods per capitalyear and the decentralization models.

Index terms: school feeding, nutrition programmes and policies, centralization, decentralization.

\section{N T R O D U Ç Ã O}

Este texto aborda o programa de alimentação escolar no Estado de Mato Grosso, que sofreu os reflexos das características do padrão de intervenção do governo federal em seu formato e organização e foi influenciado, ainda, pelas decisões e adesões das diferentes gestões dos governos mato-grossenses, as quais the conferiu diferentes graus de importância e prioridade.

Foram analisados, inicialmente, o padrão centralizado do programa na instância do governo federal e os ensaios de sua descentralização, emanados de estratégias dos órgãos federais, abrangendo, primeiramente e de forma bastante restrita, experiências em poucos estados da federação, estendidas a seguir a outros estados, incluindo o de Mato Grosso, a partir da segunda metade da década de 1980. Uma vez alterado o padrão centralizado daquela política em direção a um novo padrão descentralizado, desde o início da década de 1990, foram então examinados os traços mais gerais deste processo.

As diferentes intervenções dos governos estaduais, no período de 1979 a 1995, articularam-se às da instância federal e influenciaram o programa de alimentação escolar quanto a sua formatação e organização institucional nos órgãos estaduais de educação. No entanto, mudanças substantivas ocorreram quando o padrão centralizado deste projeto foi alterado.
Embora esta pesquisa contemple as intervenções governamentais (federais e estaduais) na organização do programa de merenda escolar, a análise empreendida enfatiza, principalmente, a instância mato-grossense no período de 1979 a 1995, coincidindo com a primeira gestão governamental, após a divisão de Mato Grosso em 1977.

O estudo valeu-se da coleta e análise de dados secundários (documentos, bibliografia específica, planos governamentais, relatórios técnicos) e primários, obtidos através de 20 entrevistas realizadas com agentes institucionais que participaram, no passado e no momento da pesquisa, dos programas estaduais de merenda escolar. O uso de ambas as fontes de dados permitiu reconstituir e analisar o padrão de intervenção daquela política governamental estadual, bem como demonstrar alguns indicadores de desempenho do projeto obtidos conforme a disponibilidade dos dados oficiais do mesmo, consultados na pesquisa.

Este artigo baseia-se no estudo de Spinelli (1998), apresentado como tese de doutoramento, a qual foi adaptada para esta publicação.

\section{Os programas federais de merenda escolar}

A intervenção governamental federal na suplementação alimentar da população escolar é das mais antigas e permanentes, no âmbito das 
políticas social e assistencial. A montagem das estruturas organizacionais ligadas ao programa de alimentação escolar transitou, na sua origem, ora nos órgãos campanhistas autônomos, ora nos vinculados aos setores de educação e de saúde. O projeto passou, então, a ser definitivamente de responsabilidade do setor educacional, tal como se encontra atualmente configurado. Sua gestão foi fortemente centralizada na instância federal, seguida de ensaios pontuais descentralizadores, processo este incrementado na década de 1990, sob modalidades e ritmos diferentes nas unidades da federação.

A retrospectiva dos empreendimentos na área de suplementação alimentar mostra, na fase de introdução do sistema de proteção social no Brasil de 1930 a 1964, a preocupação governamental com a alimentação escolar, por influência do grupo dos nutrólogos sociais, entre eles, Josué de Castro. No período de 1952 a 1955, a Campanha da Merenda Escolar (CME), então vinculada à Comissão Nacional de Alimentação, operou em poucas escolas dos estados da Bahia, Pernambuco, Pará e Espírito Santo. Esta intervenção integrou-se ao Primeiro Plano Nacional de Alimentação e Nutrição (Coimbra et al., 1982; L'Abbate, 1982; Peliano, 1988). De 1953 a 1967, o Departamento Nacional da Criança, ligado ao Ministério da Saúde e conveniado ao Fundo das Nações Unidas para a Infância, atuou nos estados nordestinos, distribuindo leite em pó às gestantes, nutrizes e pré-escolares (Canesqui, 1990).

Evidenciaram-se, nas iniciativas governamentais federais, a fragmentação e a superposição de diferentes órgãos. A concepção dominante sobre a suplementação alimentar aos escolares estava, naquele primeiro momento, baseada nas idéias dos nutrólogos que preconizavam a importância da mudança no sistema de produção, para enfrentar o problema da fome e promover a educação infantil, visando "o corretismo alimentar" (Coimbra et al., 1982; L'Abbate, 1982).
Entre 1965 e 1980, período de consolidação institucional do sistema de proteção social, o programa ganhou abrangência nacional sob forma campanhista e com gerência centralizada na Campanha Nacional de Alimentação Escolar (CNAE), constituída como superintendência federal, com fortes autonomias técnica e administrativa e poder de negociação na captação de recursos internacionais. A Campanha subordinou-se ao Departamento Nacional de Educação do Ministério de Educação até 1981 .

A CNAE expandiu-se no território nacional e manteve representações nos estados, atuando sob rígida influência militar durante o regime autoritário. A superintendência federal, ora incorporou mecanismos administrativos e decisórios desconcentradores, fortalecendo as instâncias regionais, ora reforçou o âmbito federal, mantendo maiores graus de centralização decisória e administrativa. As estruturas regionais, fragilizadas nas relações intergovernamentais durante o estado autoritário, assumiram sobretudo as características de um estado unitário quase em detrimento dos fundamentos federativos (Almeida, 1995).

Enquanto as políticas sociais, no período 1965-1980, expandiram-se centralizadas, fragmentadas institucionalmente e de forma privatista, a política de Alimentação e Nutrição tentava inscrever-se nas diretrizes do II Programa Nacional de Alimentação e Nutrição (PRONAN) de 1976 a 1980 e submetia-se aos esforços coordenadores do Instituto Nacional de Alimentação e Nutrição (INAN), órgão ligado ao Ministério da Saúde que pretendia comandar centralizadamente todos os programas de suplementação alimentar.

O INAN quis absorver as atribuições da Campanha Nacional de Alimentação Escolar, mas não teve êxito no seu desmonte e na alteração do gerenciamento do programa, o qual não se submeteu às diretrizes daquele órgão nem às do II PRONAM. Este fato mostrou resistências da burocracia ligada à CNAE e disputas na partilha 
do poder das instituições responsáveis por estes empreendimentos.

O próprio INAN propôs programas de suplementação alimentar dirigidos aos trabalhadores, ao grupo materno-infantil e aos escolares, privilegiando as regiões mais pobres, e pretendeu, concomitantemente, introduzir um conjunto de inovações naquela política, entre elas: integrar os vários ministérios; estimular a produção de produtos básicos; interferir na cadeia de abastecimento; adquirir gêneros alimentícios do pequeno produtor; e garantir preços mais competitivos.

As avaliações do II PRONAN apontaram, entre os fatores que contribuíram para o menor êxito dos seus programas, a falta de apoio político e orçamentário, seu uso clientelístico, a falta de pontualidade das ações implementadas, as quais foram incapazes de reverter a atuação conservadora e exclusiva na suplementação alimentar, restrita à mera distribuição de alimentos (Peliano, 1988).

Uma vez consolidado e expandido o sistema de proteção social brasileiro, suas reestruturações, entre 1981 e 1993, buscaram, de um lado, conservar e, de outro, redefinir o perfil das políticas sociais, isto é, descentralizá-las e universalizá-las. Pode-se incluir nestes ensaios de reestruturação conservadora a extinção da Campanha Nacional de Alimentação Escolar em 1981; a criação do Instituto Nacional de Assistência ao Educando (INAE) em 1981 e substituído pela Fundação da Assistência ao Estudante (FAE/MEC) em 1983, encarregado do Programa Nacional de Alimentação Escolar (PNAE) até 1997.

O PNAE teve como alvo as crianças matriculadas na pré-escola e nos estabelecimentos de ensino básico e fundamental (oficiais e filantrópicos), proporcionando-lhes a assistência alimentar suplementar, cujo conteúdo nutricional visava cobrir de $15 \%$ a $30 \%$ das necessidades nutricionais diárias dos alunos, durante 180 dias letivos.
A FAE foi responsável pelo financiamento, desenho e gerenciamento do programa e manteve centralizado o processo de aquisição de gêneros alimentícios. Os alimentos formulados e industrializados passaram a ser comprados de um conjunto selecionado de poucas empresas, através de licitação pública, contando com o apoio dos mecanismos instituídos entre a própria FAE e a Secretaria de Abastecimento (no plano federal), enquanto os produtos básicos passaram a ser adquiridos nas instâncias estaduais, a partir do momento em que se regionalizaram as compras.

O sistema centralizado de aquisição alimentar absorveu o maior volume dos recursos financeiros do programa (Núcleo de Estudos..., 1994), afetando a sua operacionalização e a eficácia dos resultados, em conseqüência de um conjunto de distorções (sistemas complexos de fornecimento e armazenamento dos produtos, cartelização dos fornecedores, elevação dos custos da merenda, entre outros). A merenda escolar não condizia com os hábitos dos alunos, pois os cardápios eram padronizados em função daquele mecanismo. Somente em 1994 este processo de compras foi desativado, favorecendo os esforços descentralizadores deste empreendimento a partir de 1995.

O PNAE experimentou, em 1983, inovações como a descentralização (estadualização com municipalização) nos estados do Rio de Janeiro e São Paulo. Órgãos estaduais (de educação ou de planejamento) passaram a coordenar o programa, encarregando-se do seu gerenciamento e articulação com as prefeituras dos estados. Esta experiência abarcou 90\% dos municípios no Estado de São Paulo (Núcleo de Estudos..., 1989). À instância estadual cumpriam as funções de compras, capacitação de pessoal, controle, supervisão e provimento de apoios. Coube à FAE fortalecer os governos estaduais e repassar-Ihes algumas atribuições.

Novamente a FAE, no período 1986 a 1988, estimulou a descentralização, através da municipalização, repassando certas atribuições e funções aos municípios, reservando a si própria a 
responsabilidade pelo financiamento, normatização, compras dos alimentos formulados e industrializados. Coube às prefeituras o gerenciamento e a operacionalização do programa, incluindo a aquisição de alimentos básicos e in natura dos produtores locais (cooperativas, indústrias e produtores rurais de pequeno e médio porte), estimulando as economias locais e aproximando o cardápio aos hábitos alimentares dos alunos.

As instâncias estaduais responsabilizaramse pelas seguintes atividades: elaboração dos cardápios e das pautas dos alimentos a serem adquiridos, análise dos valores nutricionais e dos custos, aquisição dos produtos básicos e controle da qualidade dos alimentos.

A municipalização do programa restringiu-se, em 1986, a apenas 83 municípios do país, e foi ampliado para 154 em 1987 e 184 em 1988, quando foi desativada (Fundação de Assistência..., 1986). Sob o ponto de vista regional, este processo privilegiou mais os municípios das regiões Nordeste, Sudeste e Sul do que os pertencentes às regiões Norte e Centro-Oeste, onde foi mais fraco o desempenho do programa.

Este processo descentralizador não foi avaliado sistematicamente nos seus êxitos e fracassos. O sistema centralizado de compras alimentares das instâncias estaduais e federal tornou compulsórios e bastante desequilibrados os gastos com a aquisição de produtos alimentares formulados e industrializados em relação aos produtos básicos. Além disso, a FAE apontou dificuldades operacionais, enfrentadas pelos municípios na prestação de contas, deficiências gerenciais e morosidade na liberação dos repasses dos recursos, afetando portanto a regularidade do programa. As inovações implementadas referiram-se ao uso de produtos regionais nos cardápios, aproximando-os dos hábitos alimentares locais e aos estímulos à produção local e à participação da comunidade escolar. Mas estas experiências foram ainda insuficientes para mudar o padrão centralizado do programa.
Argumentos e motivações democráticas apoiaram a descentralização e Ihe foram favoráveis as iniciativas da burocracia governamental federal e a adesão dos prefeitos e governadores. Entretanto, forças contrárias barraram a continuidade do processo, resultando na centralização do programa até 1993, devido ao grande interesse das indústrias alimentícias de formulados e industrializados, beneficiadas pelo sistema de compra centralizado e, portanto, resistentes aos esforços descentralizadores.

A descentralização da suplementação alimentar aos estudantes do ensino básico respaldou-se na Constituição de 1988, que propôs atender ao educando com material escolar, transporte e assistência à saúde e alimentar. Estas ações traduziram-se no dever do Estado de financiá-los através das contribuições sociais e de outros recursos orçamentários destinados à educação básica.

A crise do PNAE, no início da década de 1990, foi reconhecida oficialmente pelo Conselho Nacional de Secretários Estaduais de Educação (CONSED). Este órgão junto com a União de Dirigentes Municipais de Educação (UNDIME) e a frente Municipalista de Prefeitos foram contrários ao sistema centralizado do programa, dado o seu gigantismo, ineficácia, consumo elevado de recursos financeiros e deficiências no controle da qualidade dos alimentos. Os alimentos oferecidos não se adequavam aos hábitos dos alunos; suas perdas e deterioração eram grandes e a permanente descontinuidade deste empreendimento comprometia a eqüidade no atendimento aos beneficiários.

A sugestão foi a descentralização dos recursos financeiros destinados à merenda dos municípios, intercedida pelas Secretarias Estaduais de Educação. A adesão dos municípios seria voluntária, uma vez garantidos os pré-requisitos essenciais à administração do programa (Peliano \& Begin, 1992).

A conjuntura de crise das políticas sociais e do próprio PNAE de 1989 a 1993 permitiu outros apoios emanados da burocracia governamental 
a favor da descentralização, reunindo argumentos democratizantes ou eficientistas, fortalecedores do processo. E, embora a descentralização não estivesse diretamente na pauta das demandas da sociedade civil, aglutinada em torno do movimento nacional de Ação da Cidadania Contra a Fome e Miséria empreendido naquela conjuntura, os programas sociais foram reforçados por este ato, entre eles os de alimentação, apesar de os resultados das intervenções terem sido modestos (Núcleo de Estudos..., 1994).

Finalmente, a descentralização do PNAE oficializou-se em 1993, sob forte vertente municipalista, restringindo-se primeiramente às capitais e a seguir às cidades com mais de 50 mil habitantes e aos municípios que haviam passado pela experiência anterior de municipalização, promovida por iniciativa da FAE, entre 1986 e 1989. A meta da FAE era encarregar todos os municípios brasileiros da aquisição, armazenamento e distribuição dos alimentos, sendo voluntária sua adesão ao programa, uma vez comprovadas por eles as condições de infra-estrutura e de recursos humanos, a capacidade administrativa e o funcionamento dos conselhos de alimentação escolar, requisitos estes de baixa complexidade para serem cumpridos.

Competia à FAE - MEC definir a política de descentralização, estabelecer a normatização básica do programa, distribuir eqüitativamente os recursos financeiros mediante o uso de indicadores específicos, repassar esta verba sob a forma de convênios firmados com os estados e/ou municípios e, ainda, exercer as atividades de acompanhamento, controle e avaliação da execução deste empreendimento.

As Secretarias Estaduais de Educação receberam a incumbência de prover a rede estadual não municipalizada e os municípios que não tinham aderido à descentralização do programa e de assessorar técnica e administrativamente aqueles que haviam assumido o gerenciamento da merenda escolar.

As prefeituras executavam o programa e para isto deveriam comprovar capacidades institucionais. Elas se encarregavam de elaborar os cardápios, adquirir os alimentos, realizar o seu controle de qualidade, articuladas com a Vigilância Sanitária e inspeção agrícola, criar o conselho de alimentação escolar e prestar contas diretamente à $\mathrm{FAE}$.

A celebração dos convênios entre FAE e prefeituras foi rigorosamente normatizada pela instância federal. Os municípios endividados junto ao governo federal, os de menor porte, os recém-criados, os pobres e desprovidos de infra-estruturas administrativa e organizacional tiveram dificuldades em atender aos requisitos exigidos para aderirem à municipalização ou darem continuidade à implementação do programa.

Aos conselhos de alimentação escolar cabiam fiscalizar a aplicação dos recursos, seguindo o princípio do estímulo à atuação da comunidade escolar (pais de alunos, professores e funcionários) e à ampliação da participação social na gestão de planos governamentais, mediante o exercício de atribuições bem demarcadas.

Não foi avaliada sistematicamente, no âmbito nacional, a implementação desta etapa descentralizada, a qual envolveu basicamente o repasse de recursos e atribuições às unidades subnacionais de governo sob o comando da FAE. Participaram da fase experimental deste processo 23 capitais dos estados. Dos municípios com mais de 50 mil habitantes, 310 municipalizaram a merenda escolar em 1993 e 591 no ano seguinte (Fundação de Assistência..., 1994), número inferior a $10 \%$ do total de municípios existentes no país.

O processo de descentralização, pela via da municipalização, cresceu a partir de 1994, quando os problemas orçamentários que afetaram seriamente o desempenho do programa no período de 1991 a 1993 foram superados e um maior volume de recursos financeiros federais foi-lhe destinado. As atribuições e responsabilidades dos diferentes entes federados envolvidos neste empreendimento foram melhores definidas, fortalecendo a capacidade 
decisória das instâncias subnacionais de governo e sempre respeitando o princípio de adesão voluntária dos membros conveniados, dentro de um estado federativo, no âmbito do qual ocorria a descentralização.

A estratégia descentralizada imprimida pela $F A E$, no período de 1993 a 1995, foi gradual e diferiu substantivamente da implementada em 1986, por afetar a estrutura centralizada do programa mediante a transferência de atribuições, de parcela do poder decisório e de gestão e da instância federal para os demais níveis subnacionais de governo. Foi também demonstrado o seu sistema centralizado de compras, que dificultava sobremaneira o processo, reduzindo-se as resistências apresentadas pela cultura institucional centralista, alimentada durante longos anos. Além da municipalização, a FAE previu a estadualização, garantindo a merenda escolar aos municípios que não aderiram ao processo, os quais eram atendidos pelo estado.

A expansão da descentralização foi um processo nacional e, no período de 1993 a 1996, os convênios assinados entre a FAE e os municípios passaram de 1265 para 3257 (Brasil..., 1998), com rápido avanço da municipalização. A modalidade estadualizada permaneceu por certo tempo e tendeu a descentralizar os recursos do programa para as escolas, ação esta conhecida como autonomização da escola.

Este estágio durou até 1997, quando a FAE foi extinta e substituída pelo Fundo Nacional de Desenvolvimento da Educação (FNDE). Este deu continuidade à descentralização, mas o exame desta nova etapa escapa aos propósitos deste texto, embora tenha ele sido melhor acompanhado e avaliado, através de estudos recentes (Brasil..., 1998).

\section{Programas de merenda escolar no estado de Mato Grosso}

A retrospectiva das intervenções governamentais na merenda escolar no Estado de Mato Grosso permite apontar a ausência de iniciativas estaduais independentes das federais. O programa de merenda escolar, desde a sua emergência, na década de 1950, até a descentralização, na década de 1990, foi muito dependente das ações dos órgãos governamentais federais.

Primeiramente, o padrão de intervenção foi centralizado e dependente do financiamento, das normas, do sistema de aquisição dos alimentos, da supervisão e do controle das agências federais. Posteriormente, a descentralização transferiu a gestão, os recursos e as atribuições da instância federal de governo para os estados e municípios, com variações no seu ritmo, modalidade e intensidade nas diferentes regiões do país.

No período de implantação do sistema de proteção social brasileiro, isto é, de 1930 a 1964, alguns órgãos federais, a Comissão Nacional de Alimentação, responsável pela Campanha de Merenda Escolar, e o Departamento Nacional da Criança promoveram programas pontuais em alguns estados. Na parte sul do Estado de Mato Grosso esteve o braço regional paulista da Campanha de Alimentação Escolar e na parte Amazônica, situada na região Norte, esteve encarregada a representação regional da Superintendência do Plano de Valorização Econômica da Amazônia (SPVEA), fragmentando-se portanto, institucionalmente, o programa no Estado. A Campanha de Merenda Escolar atendeu a região Centro-Oeste, beneficiando apenas 46\% dos municípios, no período de 1956 a 1958 (Coimbra et al., 1982).

A Campanha Nacional de Alimentação Escolar (CNAE) expandiu o programa em consonância com a ideologia da Segurança Nacional e de Desenvolvimento do regime militar, cioso por legitimar-se e controlar as regiões fronteiriças. No início da década de 1970, o programa cobriu municípios estratégicos mato-grossenses, entre eles: Rondonópolis, Rosário do Oeste, Nortelândia, Barra do Garça e Campo Grande. Sua execução 
dependeu de recursos financeiros federais, oriundos dos convênios estabelecidos entre a CNAE e os governos estadual e municipais.

Sob o ponto de vista organizacional, a CNAE, centralizada na instância federal, dispôs de uma coordenação regional no Estado, desarticulada da Secretaria de Estado de Educação e Cultura (SEEC). Os gêneros alimentícios e os recursos de apoio ao programa eram repassados ao estado e aos municípios, através daquele órgão, evidenciando um modelo típico de desconcentração institucional, com delegação de atribuições às instâncias hierarquicamente dependentes, dentro de uma mesma organização (Junqueira, 1997).

As séries históricas de dados da FAE, obtidas para o antigo Estado de Mato Grosso na década de 1970, indicaram grande expansão no número de municípios atendidos pelo programa. Entre 1974 e 1980, $91 \%$ deles foram abrangidos, enquanto apenas $70 \%$ deles estavam incluídos em 1970. Neste mesmo ano, foram atendidas $43 \%$ das escolas, expandindo para 91\% em 1980 (Fundação de Assistência..., 1985). Os dados registrados sugerem que a cobertura dos dias letivos constituiu-se no ponto mais crítico, permanecendo em torno de $43 \%$ da meta estabelecida no ano de 1970 , subindo para $65 \%$ em 1975 e atingindo $91 \%$ em 1980.

O Estado do Mato Grosso dividiu-se em dois em 1977, designados de Mato Grosso e Mato Grosso do Sul. As várias gestões governamentais de Mato Grosso, após aquela separação, prioriorizaram o setor educacional. O mesmo não ocorreu com as prioridades conferidas à Merenda Escolar, cujo programa apresentou uma regularidade bastante oscilante, durante as diferentes gestões estaduais.

Assim sendo, o Primeiro Plano Geral de Governo do novo Estado de Mato Grosso para o período de 1980 a 1983, sob a gestão de Frederico Carlos S. Campos, assegurou o desenvolvimento agrícola de exportação, a agropecuária e a colonização, através dos assentamentos dos migrantes, e preocupou-se com a área educacional, promovendo a ampliação da rede física e a capacitação de recursos humanos (Mato Grosso..., 1980).

Neste período o programa de alimentação escolar permaneceu dependente da CNAE e de sua coordenação estadual. No âmbito da SEEC, foi criada uma estrutura organizacional específica para gestão das políticas assistenciais destinados aos educandos, seguindo as diretrizes do MEC e as iniciativas locais. Houve uma reestruturação da secretaria, com a criação da Coordenadoria de Apoio ao Educando (CAE), o qual contou com a Divisão de Assistência ao Educando, que, entre outras atividades, respondia pelas práticas agrícolas, hortas, restaurantes e saúde escolar. Paralelamente a esta estrutura administrativa a CNAE continuava responsável pelo programa estadual.

Uma vez extinta a CNAE, o Instituto Nacional de Alimentação Escolar (INAE), durante um curto período, unificando várias ações federais de assistência ao estudante, encarregou-se do programa, cuja execução no Estado foi sendo gradativamente transferida à SEEC, enquanto sua formulação e seu financiamento ficaram sob o controle da agência federal. Sob a gestão do INAE, o programa estadual foi executado pelas Delegacias Regionais do Ministério de Educação e Cultura, articuladas à SEEC, através da Coordenadoria de Apoio ao Educando.

Criada a FAE, em 1983, a SEEC assinou o convênio para executar o programa no Estado e promover reformas administrativas, resultando em mudanças na sua estrutura organizacional. Em 1984, a Coordenadoria de Apoio ao Educando (CAE) criou a Divisão de Educação Alimentar e Saúde ao Educando, seu responsável até 1991.

A gestão do governo estadual de Júlio Campos de 1983 a 1987 priorizou o projeto e, a partir de 1984, a SEEC, através da CAE, assumiu várias responsabilidades, entre elas a formulação dos cardápios, a realização de testes de aceitabilidade dos alimentos formulados e a execução das várias atividades de supervisão, treinamento, aquisição e repasse dos gêneros aos 
municípios, seguindo as normas da FAE. Os alimentos básicos eram adquiridos em Mato Grosso, pela Companhia Brasileira de Abastecimento (COBAL), e os formulados e industrializados, na instância federal. Os convênios garantiam o repasse dos alimentos adquiridos na instância federal ao estado, e a SEEC realizava acordos com as prefeituras para armazenagem e distribuição da merenda às escolas municipais.

Nos anos de 1985 e 1986, quando a FAE vivia um momento de diretriz descentralizada (municipalizante), o programa de alimentação escolar teve como clientela os alunos matriculados nas pré-escolas e escolas de primeiro grau e no ensino supletivo (diurno e noturno) e estendeu-se a 54 municípios mato-grossenses, além da capital.

Os relatos de alguns agentes decisores e implementadores entrevistados identificaram, no período, a grande complexidade e ineficiência do sistema de compras centralizado e o seu reflexo no atendimento à qualidade nutricional dos alimentos ofertados à clientela, apesar da expansão da cobertura do programa. Entre as deficiências apontadas estava o aumento das quantidades de alimentos como arroz, farinha e macarrão, de custo mais barato, em detrimento de produtos de origem animal, de preços mais elevados e de maior valor protéico. Esta atitude suscitava grande descontentamento dos prefeitos e secretários da educação, acarretando pressões sobre o órgão administrativo e os profissionais responsáveis, entre os quais estavam os nutricionistas.

Esta gestão governamental apoiou o "Programa Irmãozinho", uma intervenção do PNAE, implementada desde o segundo semestre de 1986 até 1990, ampliando a oferta de alimentos às crianças, através das escolas e de 382 postos de atendimentos. Este empreendimento, financiado pela FAE/MEC, destinou-se às crianças em idade pré-escolar e aos irmãos dos alunos matriculados no ensino básico. Ele funcionou junto ao PNAE e ampliou a cobertura dos beneficiários e a quantidade per capita dos alimentos ofertados. Verifica-se que não foi fortuito, pois os técnicos entrevistados para esta pesquisa rememoraram o período como de "grande fartura da merenda", mas reconheceram o uso clientelista do programa e os rendimentos políticos substantivos por ele proporcionados ao governo estadual junto à população e, em especial, em sua relação com os municípios interioranos.

Na gestão seguinte (1987-1991), do governo Carlos Gomes Bezerra, o programa de merenda escolar oscilou bastante e sofreu descontinuidade, particularmente a partir de 1989, como reflexo da crise nacional do próprio PNAE, que se arrastou até 1992. Apesar disto, algumas inovações se introduziram, como o estímulo às hortas escolares, implementadas em algumas escolas de Cuiabá, e a construção de refeitórios em outras cidades, melhorando, em parte, a infra-estrutura de apoio ao programa.

O plano deste governo lançou as bases da escola democrática, favorecendo os processos decisórios participativos e as inovações pedagógicas, e desconcentrou a gestão, dando maior autonomia às instâncias gestoras regionais da SEEC e às escolas. Mas o programa de merenda escolar não foi afetado por estas inovações e seguiu sua rotina, centralizando as compras alimentares e demais atividades (Spinelli, 1998).

\section{Crise do PNAE e a descentralização}

A crise do PNAE teve como um dos nós críticos o sistema de compras centralizado nas instâncias federal e estadual. Foram instaladas auditorias em vários estados da federação, incluindo o de Mato Grosso, devido às irregularidades constatadas e ao impacto negativo sobre a continuidade do programa, no período de 1989 a 1992.

O Plano Plurianual de 1992 a 1995 (Mato Grosso..., 1992), do governo Jaime Campos, previu um processo de reforma administrativa 
para reestruturar os órgãos gerenciadores deste empreendimento. Foram extintas a CAE e a Divisão de Educação e Saúde Escolar e o programa subordinou-se a uma coordenadoria técnica, inserida em uma outra divisão administrativa, cuja atribuição era executar a política de merenda escolar da FAE. Nas opiniões dos técnicos entrevistados este deslocamento administrativo significou "perda de status" para o programa no interior da hierarquia da SEEC. As atividades restringiram-se à oferta de apenas três cursos de treinamento aos municípios e à aquisição e distribuição de alimentos.

Apesar do forte uso clientelista e político do programa, uma avaliação ex-post de alguns efeitos institucionais de sua implementação e desempenho, constatados nesta pesquisa, permite afirmar que o ensaio descentralizado teve saldos positivos, como o acúmulo de experiências institucionais e burocráticas, o preparo de técnicos e a articulação com os municípios. Este resultado favorável não ocorreu quando o programa permaneceu absolutamente centralizado na instância federal. Contudo, não estava desfeita a tradição institucional centralizadora da instância estadual na operacionalização e gerenciamento deste empreendimento, pois ela era garantida pela permanência do sistema de compras centralizado e pelas formas de supervisão e controle do programa, com baixo grau de estímulo ao repasse de responsabilidade de gestão e atribuições aos municípios.

O governo de Dante de Oliveira estabeleceu um Plano de Metas de 1995 a 2006 (Mato Grosso..., 1995a) com diretriz descentralizadora do setor educacional, incluindo a gestão democrática e a partilha de atribuições entre estado, município e comunidade escolar no gerenciamento da unidades escolares (autonomia da escola), uma das vertentes descentralizadas da gestão educacional, respaldada na Constituição Estadual de 1989. Isto favoreceu, posteriormente, as iniciativas governamentais de repasse de recursos financeiros, funções e atribuições às escolas no programa de merenda escolar. Quando este estudo foi realizado esta modalidade de descentralização ainda não estava implementada.

Uma nova reforma da SEEC criou o Núcleo de Alimentação Escolar (NAE), com as seguintes responsabilidades: suprimentos de alimentos aos municípios não descentralizados; apoio aos municípios que descentralizaram o programa em seu território; capacitação de recursos humanos; supervisão; acompanhamento e avaliação; elaboração dos cardápios; controle de qualidade dos alimentos em articulação com a Universidade Federal de Mato Grosso. O Núcleo propôs a definição das atribuições das diferentes instituições envolvidas e o reequipamento das escolas, necessário ao melhor desempenho do programa (Mato Grosso..., 1995c).

O período de 1993 a 1995 foi marcado pela transição do processo de descentralização, instalado por influência da estratégia descentralizada da $F A E$, que afetou o formato centralizado anterior. Foram três as modalidades identificadas na pesquisa:

1)a estadualização, mediante $O$ estabelecimento de convênio entre a FAE e SEEC e entre esta e os municípios que não tinham aderido ao processo de municipalização, atendendo os alunos matriculados nas escolas estaduais e municipais, e cobrindo $42,7 \%$ das cidades;

2) a municipalização, atingindo $42,7 \%$ dos municípios que fizeram convênios com a FAE e assumiram integralmente o gerenciamento do programa e atendimento, no seu espaço territorial, das redes de ensino federal, estadual e municipal;

3)o tipo misto de descentralização, combinando a estadualização com a municipalização, para atendimento das escolas situadas na mesma base territorial, e abrangendo 14,6\% dos municípios, entre eles os de maior porte: Cuiabá (capital), Rondonópolis e Várzea Grande (Mato Grosso..., 1997). 
A taxa de adesão dos municípios mato-grossenses à descentralização foi progressiva. Em 1993 apenas 5,1\% do total de 117 municípios aderiram ao processo. A taxa elevou-se para 15,4\% no ano seguinte e para 53,0\% em 1995.

\section{O desempenho do Programa de Merenda Escolar: 1980 a 1995}

Observar que entre 1983 e 1992 todos os municípios eram atendidos pela merenda escolar e o número de alunos atendidos oscilou bastante. No ano de 1988 o atendimento aos beneficiários ultrapassou a meta de $100 \%$ devido ao "Programa Irmãozinho" (122,7\%). Entre 1989 e 1991 decresceu o percentual de alunos atendidos, ficando em torno de $85,0 \%$, e caiu para $68,6 \%$ em 1992, coincidindo com a crise do PNAE. Os dias de atendimento apresentaram uma variabilidade ampla. A meta de cobertura de 180 dias letivos foi alcançada nos anos de 1982, 1986 e 1987. Entre 1990 e 1992, o programa apenas cobriu a terça parte do ano escolar, evidenciando o seu fraco desempenho no atendimento aos beneficiários (Figura 1).
$\mathrm{O}$ atendimento dos dias letivos, segundo a FAE, deveria ser de 180 dias. Enquanto 100\% da meta foi alcançada apenas nos anos de 1986 e 1987, ela foi ultrapassada em 1988, chegando a 122,7\%, devido ao programa "Irmãozinho". De 1990 a 1992, o programa apenas cobriu a terça parte do ano escolar, evidenciando o seu fraco desempenho no atendimento aos beneficiários.

A partir de 1993 a SEEC passou a atender apenas os municípios que não tinham aderido à descentralização e a sua própria rede estadual, tendo decrescido gradativamente o número de alunos atendidos, o qual passou de $541688 \mathrm{em}$ 1993 para 341253 em 1995, devido ao avanço da municipalização. A cobertura dos dias letivos ficou em $31 \%$ da meta em 1993, saltou para $82,2 \%$ em 1994 e caiu para 33,0\% em 1995. O consumo de alimentos per capita/ano caiu de 9,1 kg em 1994 para 5,8 kg em 1995, distanciando-se bastante dos 10,4 kg consumidos em 1986 e dos 2,7 k, em 1991, época de crise do programa. (Fundação de Assistência..., 1986; Mato Grosso..., 1995b) Os gastos per capita/ano comportaram-se inversamente e atingiram $R \$ 7,10$ em 1994 e $R \$ 9,40$ em 1995, quando o custo aluno/dia aumentou para $\mathrm{R} \$ 0,16$.

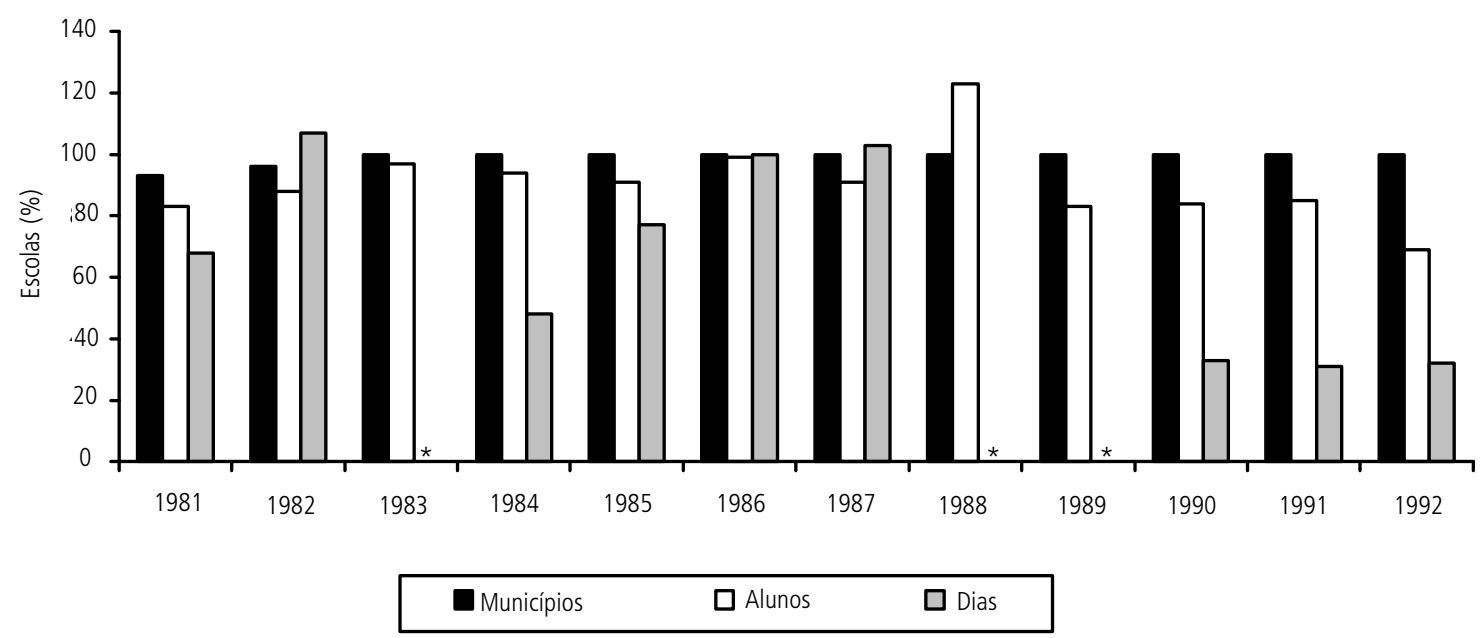

Figura 1. Programa Nacional de Alimentação Escolar, segundo cobertura de municípios, alunos e dias letivos, no período de 1981 a 1992 , Mato Grosso.

Fonte: 1981-1984 (Fundação de Assistência..., 1985).

1985-1987 (Mato Grosso..., 1992).

1989 (Mato Grosso ... 1990).

1988-1990 (Fundação de Assistência..., 1991).

1991-1992 (Núcleo de Estudos. 1994).

Nota: ${ }^{*}$ Dados não disponíveis para cobertura dos dias letivos. 


\section{O NCLUSÃ O}

Com este estudo captou-se a fase de transição do programa examinado, do padrão centralizado para o descentralizado. Seria prematuro demonstrar todos os seus efeitos, pois os indicadores de desempenho evidenciaram grandes oscilações. Além disso, a cobertura dos dias letivos ficou aquém das metas estabelecidas, comprometendo a análise dos resultados do projeto, embora no momento inicial dos esforços descentralizadores o atendimento de 180 dias tinha sido alcançado.

O acúmulo de experiências e de aprendizagem institucional e as adesões das gestões estaduais de governo foram condições favoráveis ao avanço do processo descentralizador. A tendência agora é descentralizar o programa para as escolas e abarcar um número maior de municípios.

Os períodos marcados pelo modelo centralizado mostraram muitas distorções, apontadas no decorrer deste trabalho, mas, inclusive nestes momentos, o programa tendeu a universalizar-se nos municípios.

Observa-se, analisando outros aspectos desta pesquisa, que as necessidades nutricionais dos alunos podem não ter sido completamente atendidas, em virtude de os indicadores das quantidades per capita/ano consumidas serem insuficientes para dimensioná-las e terem sido mais elevados apenas no período de 1985 a 1986, aumento observado em todo o país, chegando a $11 \mathrm{~kg}$ per capita/ano (Núcleo de Estudos..., 1994).

Finalmente, o processo de descentralizacão é a tônica maior do programa atualmente, desenvolvido sob diferentes modalidades e induzido pelo governo federal, com repasse de atribuições, gestão e recursos às instâncias subnacionais de governo. Para redesenhar o estado federativo e criar bases mais cooperativas, alguns problemas precisam ser solucionados, entre os quais o reordenamento das relações intergovernamentais e o equacionamento das disparidades inter e intra-regionais, que afetam as políticas sociais em geral.

\section{REFERÊ NCIAS B I B LIOGRÁ FICAS}

ALMEIDA, M.H.T. Federalismo e políticas sociais. Revista Brasileira de Ciências Sociais, v.10, n.28, p.88-108, 1995.

BRASIL. Ministério da Educação e Cultura. Avaliação da descentralização de recursos do FNDE e da merenda escolar: síntese de resultados. Brasília, 1998. p.87-133.

CANESQUI, A.M. Saúde pública e assistência à maternidade e à infância. Relatório de pesquisa. Campinas: Unicamp, 1990. Mimeografado.

COIMBRA, M. et al. Comer e aprender: uma história da alimentação escolar. Belo Horizonte : INAE, 1982.

FUNDAÇÃO DE ASSISTÊNCIA AO ESTUDANTE. Séries históricas 1970-1984. Brasília : MEC, 1985. p.45.

FUNDAÇÃO DE ASSISTÊNCIA AO ESTUDANTE. Relatório anual de atividades - FAE 1986. Brasília : MEC, 1986. 88p.

FUNDAÇÃO DE ASSISTÊNCIA AO ESTUDANTE. Relatório anual de atividades - FAE 1988. Brasília : MEC, 1988. 69p.

FUNDAÇÃO DE ASSISTÊNCIA AO ESTUDANTE. Relatórios anuais de atividades 1986 a 1990. Brasília, 1991. Mimeografado.

FUNDAÇÃO DE ASSISTÊNCIA AO ESTUDANTE. Descentralização do Programa Nacional de Alimentação Escolar. Relatório de atividades 1993-1994. Brasília, 1994. 72p.

JUNQUEIRA, L.A.P. A descentralização e a reforma do aparato estatal em saúde. In: CANESQUI, A.M. Ciências sociais e saúde. São Paulo : Hucitec, 1997. p.173-204.

L'ABBATE, S. Fome e desnutrição: os descaminhos da política social. São Paulo, 1982. 200p. Dissertação (Mestrado em Sociologia) - Faculdade de Filosofia Ciências e Letras, Universidade de São Paulo, 1982. 
MATO GROSSO. Governo do Estado. Primeiro plano geral de governo para o estado de Mato Grosso 1980-1984. Cuiabá, 1980. p.270-303.

MATO GROSSO. Governo do Estado. Plano de desenvolvimento do estado de Mato Grosso 1983-1987. Cuiabá, 1983.

MATO GROSSO. Governo do Estado. Plano plurianual 1992-1995. Cuiabá, 1992. p.71-83.

MATO GROSSO. Governo do Estado. Plano de metas Mato Grosso 1995-2006. Cuiabá, 1995a. p.66-72.

MATO GROSSO. Secretaria de Estado de Educação e Cultura. Divisão de Apoio ao Educando. Plano emergencial do programa de alimentação escolar. Cuiabá, 1995b.

MATO GROSSO. Secretaria de Estado de Educação e Cultura. Núcleo de Alimentação Escolar. Relatório gerencial do programa de alimentação escolar. Cuiabá, 1995c. 13p.

MATO GROSSO. Secretaria de Estado de Educação e Cultura. Núcleo de Alimentação Escolar. Informações sobre a descentralização do programa de alimentação escolar. Cuiabá, 1997. $5 p$.

NÚCLEO DE ESTUDOS DE POLÍTICAS PÚBLICAS. Política de alimentação e nutrição. In: NEEP. Brasil 1986: relatório sobre a situação social do país. Campinas: Unicamp, 1988. p.230-258.
NÚCLEO DE ESTUDOS DE POLITICAS PÚBLICAS. Política de alimentação e nutrição. In: NEEP. Brasil 1987: relatório sobre a situação social do país. Campinas : Unicamp, 1989. p.313-382.

NÚCLEO DE ESTUDOS DE POLÍTICAS PÚBLICAS. Estratégias para combater a pobreza no Brasil: programas, instituições e recursos. Campinas: Unicamp, 1994. p.69-92.

PELIANO, A.M.M. Os programas alimentares e nutricionais econômicos: 1980-1984. In: CHAADAD, J.P., CERVINI, R. Crise e infância no Brasil: no contexto da recessão o impacto das políticas de ajustamento econômico. São Paulo : Unicef, 1988. p.185-219.

PELIANO, A.M.M., BEGIN, N. O papel do estado na área de alimentação e nutrição. Brasília : IPEA, 1992. $12 p$

PELIANO, A.M.M. Um balanço das ações de governo no combate à fome e à miséria: 1993. Brasília : IPEA, 1994. p.18-21.

SPINELLI, M.A.S. Alimentação escolar: da centralização à descentralização. Campinas, 1998. 195p. Tese (Doutorado em Saúde Coletiva) - Faculdade de Ciências Médicas, Universidade Estadual de Campinas, 1998.

Recebido para publicação em 22 de setembro de 2000 e aceito em 5 de junho de 2001. 
